\title{
Особенности состава обменных катионов фонового аллювия и техногенных речных илов
}

\section{Янин Е.П.}

Институт геохимии и аналитическойхимии им. В.И. Вернадского РAH, Москва, yanin@geokhi.ru

Аннотация. Изучен состав обменных катионов фонового аллювия и техногенных речных илов. Установлено, что техногенные илы характеризуются высокими значениями сухого остатка, высокой обменной кислотностью и высокими содержаниями обменных ионов. Повышенная емкость поглощения, свойственная техногенным илам, обусловливает их высокую удерживающую способность по отношению к загрязняющим веществам. Это свидетельствует о потенциальной значимости илов как вторичного источника загрязнения водных систем.

Ключевые слова: техногенез, обменные катионы, фоновый аллювий, техногенные речные илы, загрязнение.

\section{Compositional features of the exchange cations of background alluvium and technogenic river silts}

\author{
Yanin E.P. \\ Vernadsky Institute of Geochemistry and Analytical Chemistry of Russian Academy of Sciences, Moscow, \\ yanin@geokhi.ru
}

Abstract. The composition of the exchange cations of the background alluvium and technogenic river silts was studied. It has been established that technogenic silts are characterized by high dry residue values, high exchange acidity and significant content of exchange ions. The increased absorption capacity characteristic for technogenic silts determines their high retention capacity with respect to pollutants. This indicates the potential importance of silts as a secondary source of pollution in aquatic systems.

Key words: technogenesis, exchange cations, background alluvium, technogenic river silts, pollution.

Важным свойством аллювиальных отложений является их физико-химическая поглотительная (обменная) способность (обменная адсорбция), которая заключается в том, что отложения способны обменивать некоторую часть содержащихся в их твердой фазе ионов (главным образом катионов) на эквивалентное количество ионов, находящихся в соприкасающемся с этой фазой раствоpe (с иловыми водами). Между катионами твердой фазы отложений и катионами водного (илового) раствора устанавливается определенное равновесие. Поглощаемый из раствора при этом катион (или катионы, если их в растворе несколько), в том или другом количестве исчезает из раствора и становится в соединения твердой фазы отложений, а вместо него в раствор переходит из твердой фазы эквивалентное количество другого или других катионов. Подобный обмен катионов может (в зависимости от их рода) в той или другой степени повлиять на физические и химические свойства отложений, так как те и другие находятся в тесной зависимости от рода катионов, входящих в поглощенном состоянии в твердую фазу отложений. Сумма всех поглощенных (обменных) катионов, могущих быть вытесненными из отложений, называется емкостью поглощения (емкостью обмена). Величина емкости обмена катионов зависит от гранулометрического и минерального состава отложений, содержания в них аморфных и органических веществ и их природы, реакции среды (Гедройц, 1955; Грим, 1967).

В техногенных ландшафтах в аллювиальном седиментогенезе участвуют значительные массы материала, появление которого в осадочном цикле связано с хозяйственной деятельностью человека (с техногенезом). Это обусловливает образование и широкое распространение в реках таких районов особой разновидности современных русловых отложений - техногенных речных илов, которые отличаются от типичного (фонового) руслового аллювия морфологическим обликом, вещественным составом, физико-химическими свойствами и геохимическими характеристиками (Янин, 
2013; Yanin, 2019). Техногенные речные илы, концентрируя значительные количества химических элементов и органических соединений (загрязняющих веществ), являются источником вторичного загрязнения водной массы и биоты (Янин, 2015). Степень закрепления различных веществ в техногенных речных илах и интенсивность их перехода в водную толщу зависят от многих факторов, но особое значение имеет именно физико-химическая поглотительная (обменная) способность отложений. Сведения о емкости обмена катионов и о составе обменных катионов техногенных речных илов в литературе практически отсутствуют. Автором был изучен состав обменного комплекса природного (фонового) аллювия и техногенных илов.

Исследования были выполнены в пределах Московской области в бассейне р. Пахры (правом притоке р. Москвы). Пробы фонового аллювия (разнозернистые русловые пески) отбирались в верховьях Пахры вне зон прямого техногенного воздействия, техногенных илов - на реках Мураниха и Петрица. Небольшая, частично зарегулированная (в верхнем течении прудом-отстойником, в среднем - дамбой) Мураниха впадает в р. Жданку (правый приток Пахры). В Мураниху длительное время поступали поверхностный сток и сточные воды аэропорта Домодедово (прежде всего, его производственных подразделений, связанные с обслуживанием и ремонтом техники). В русле Муранихи развиты типичные техногенные илы, отличающиеся высокими концентрациями широкой группы химических элементов, особенно тяжелых металлов, и значениями суммарного показателя загрязнения, отвечающих преимущественно очень высокому уровню загрязнения (Янин, 2004). Петрица имеет длину около 10 км, впадает (справа) в один из главных притоков Пахры p. Мочу. Ее русло зарегулировано прудами. В р. Петрице и в существующих на ней прудах широко распространены техногенные илы, содержащие в высоких концентрациях широкую группу химических элементов (Янин, 2004). Особенно значительной степень техногенного воздействия на водную систему Петрицы была в прошлые годы, когда в речку осуществлялся сброс сточных и ливневых вод завода «Вторцветмет» (пос. Львовский). Пробы фонового аллювия отбирались пластиковым совком (слой 0-20 см), пробы техногенных илов - буром ТБГ-1 (по возможности на всю их мощность - до 60 см и более). Пробы высушивались на воздухе в тени в хорошо проветриваемом помещении (с периодическим - 2-3 раза в день - размятием каждой пробы). Затем они просеивались через сито (капроновое) с диаметром отверстий 1 мм, квартовались и помещались в пакеты из кальки. Химико-аналитические исследования (компоненты петрохимического состава, сухой остаток, обменные ионы, $\mathrm{pH}$ ) отобранных проб выполнены по стандартным методикам (Практикум..., 2001), количество аморфного вещества определялось рентгенографическим фазовым анализом (Сидоренко, Метлова, 1989), бенз(а)пирен - спектрофлуориметрическим анализом при низких температурах (спектроскопия Э.В. Шпольского) (Алексеева, Теплицкая, 1981), нефтепродукты - флуориметрическим методом (ПНД Ф 16.1:2.21-98). Все результаты анализов даются на сухую массу образца.

Важнейшей особенностью техногенных речных илов является высокое содержание в них рентгеноаморфных веществ. Если в фоновом аллювии доля аморфной фазы составляет $~ 11 \%$, то в техногенных илах она увеличивается до 30 \% и более. Аморфное вещество, присутствующее в илах, играет важную геохимическую роль, в существенной мере определяя их значимость, с одной стороны, как концентраторов поллютантов, с другой - как потенциальных источников вторичного загрязнения водной массы при диагенетических преобразованиях отложений. Наличие в последних значительного количества рентгеноаморфного вещества существенно увеличивает их коллоидальную активность, набухание, водопроницаемость, липкость, гидрофильность. Фоновый аллювий характеризуется высокими содержаниями кремнезема и глинозема, что является следствием минерального состава - преобладание кварца, присутствие полевых шпатов (Янин, 2007). Обычно химический состав фонового аллювия закономерно близок составу природных почв и четвертичных отложений Русской равнины, являющихся основными природными источниками поставки осадочного материала в речную сеть. Техногенные илы по своему петрохимическому составу резко отличаются от фонового аллювия, что обусловлено спецификой поступающего с освоенных территорий осадочного материала (в составе поверхностного стока и сточных вод) и своеобразием геохимических условий среды техногенного осадконакопления. Они чаще всего характеризуются пониженными содер- 
жаниями кремнезема, высокими содержаниями глинозема, оксидов железа, органических веществ и ряда других соединений (табл. 1). Очень велико содержание в илах бенз(а)пирена и нефтепродуктов - типичных индикаторов техногенного загрязнения.

Результаты исследований свидетельствуют о том, что техногенные илы характеризуются (по сравнению с аллювием) чрезвычайно высокими значениями сухого остатка, высокой обменной кислотностью и значительными содержаниями обменных ионов (табл. 2, 3).

Таблица 1. Химический состав фонового аллювия и техногенных илов, \%.

Table 1. The chemical composition of the background alluvium and technogenic river silts, $\%$.

\begin{tabular}{|c|c|c|c|}
\hline \multirow{2}{*}{ Компоненты } & \multirow{2}{*}{ Фоновый аллювий } & \multicolumn{2}{|c|}{ Техногенные илы } \\
\cline { 3 - 4 } & & p. Мураниха & p. Петрица \\
\hline $\mathrm{SiO}_{2}$ & 87.64 & 58.83 & 51.27 \\
$\mathrm{TiO}_{2}$ & 0.20 & 0.72 & 0.547 \\
$\mathrm{Al}_{2} \mathrm{O}_{3}$ & 4.89 & 9.77 & 8.38 \\
$\mathrm{Fe}_{2} \mathrm{O}_{3}$ & 0.86 & 6.5 & 5.82 \\
$\mathrm{FeO}$ & 0.30 & 1.98 & 0.98 \\
$\mathrm{MnO}$ & 0.014 & 0.10 & 0.429 \\
$\mathrm{MgO}$ & 0.20 & 0.68 & 0.96 \\
$\mathrm{CaO}$ & 0.127 & 1.49 & 2.88 \\
$\mathrm{Na}_{2} \mathrm{O}$ & 0.84 & 0.51 & 0.61 \\
$\mathrm{~K}_{2} \mathrm{O}$ & 1.72 & 1.69 \\
$\mathrm{P}_{2} \mathrm{O}_{5}$ & 1.36 & 1.15 & 1.809 \\
$\mathrm{SO}_{3}$ & 0.153 & 1.15 & 0.83 \\
$\mathrm{Cумма}_{\mathrm{H}_{2} \mathrm{O}^{+}}$ & 0.028 & 20.56 & 24.77 \\
$\mathrm{H}_{2} \mathrm{O}^{-}$ & 3.26 & 100.16 & 100.975 \\
$\mathrm{CO}_{2}$ & 99.872 & 7.78 & 4.16 \\
Потери при прокаливании & 1.73 & 3.01 & 1.15 \\
Бенз(а)пирен, мг/кг & 0.33 & 0.11 & 1.12 \\
Нефтепродукты, мг/кг & 0.04 & 0.05 & 1.41 \\
& $<0.01$ & 2000 & 8100 \\
\hline
\end{tabular}

Таблица 2. Обменные ионы в фоновом аллювии и техногенных речных илах.

Table 2. Exchange ions in the background alluvium and technogenic river silts.

\begin{tabular}{|c|c|c|c|c|c|c|c|c|c|}
\hline \multirow{2}{*}{$\begin{array}{c}\text { Место } \\
\text { отбора проб }\end{array}$} & \multirow{2}{*}{$\mathrm{pH}$} & \multirow{2}{*}{$\begin{array}{c}\mathrm{CO}^{*} \\
\mathrm{мг} / 100 \text { г }\end{array}$} & \multicolumn{6}{|c|}{ мГ-эКв/100 г } & \multirow{2}{*}{$\begin{array}{l}\mathrm{OK}^{* *}, \mathrm{M \Gamma} \\
\text { ЭКВ/100 г }\end{array}$} \\
\hline & & & $\mathrm{NO}_{3}^{-}$ & $\mathrm{NH}_{4}^{+}$ & $\mathrm{Na}^{+}$ & $\mathrm{K}^{+}$ & $\mathrm{Ca}^{2+}$ & $\mathrm{Mg}^{2+}$ & \\
\hline \multicolumn{10}{|c|}{ Фоновый аллювий } \\
\hline Верховье р. Пахры & 7.4 & 11.8 & 0.01 & 0.05 & 0.01 & 0.03 & 3.62 & 1.13 & $<0.009$ \\
\hline \multicolumn{10}{|c|}{ Техногенные иль } \\
\hline Мураниха, аэропорт & 4.7 & 276.5 & 0.09 & 1.87 & 0.07 & 0.09 & 25.70 & 6.99 & 0.639 \\
\hline Петрица, верховье & 4.6 & 396.3 & 0.04 & 1.53 & 0.19 & 0.43 & 27.45 & 9.01 & 0.675 \\
\hline Петрица, верховье & 6.2 & 320.3 & 0.05 & 1.46 & 0.11 & 0.35 & 33.18 & 6.25 & 0.153 \\
\hline Петрица, Климовск & 7.4 & 301.3 & 0.05 & 0.24 & 0.11 & 0.40 & 27.45 & 6.74 & 0.054 \\
\hline Петрица, Климовск & 7.4 & 139.8 & 0.01 & 0.10 & 0.02 & 0.06 & 10.51 & 3.50 & 0.036 \\
\hline Петрица, Климовск & 7.4 & 197.5 & 0.03 & 0.14 & 0.04 & 0.15 & 13.97 & 4.01 & 0.027 \\
\hline Петрица, Климовск & 7.3 & 275.5 & 0.05 & 0.44 & 0.05 & 0.24 & 26.95 & 5.24 & 0.072 \\
\hline Устье Петрицы & 6.6 & 186.5 & 0.02 & 0.36 & 0.04 & 0.14 & 16.72 & 6.99 & 0.087 \\
\hline Среднее & 6.5 & 261.7 & 0.04 & 0.77 & 0.08 & 0.23 & 22.74 & 6.09 & 0.22 \\
\hline
\end{tabular}

Примечание - * Сухой остаток. ** Обменная кислотность. 
Если емкость катионного обмена фонового аллювия невысока - 4.84 мг-экв/100 г, то емкость катионного обмена техногенных илов существенно возрастает, достигая в некоторых случаях 38-41 мг-экв/100 г. Наибольшие значения емкости обмена катионов закономерно характерны для отложений с низкими значениями $\mathrm{pH}$. Как в фоновом аллювии, так и в техногенных илах в составе обменных катионов доминирует (69-82 \% от суммы) $\mathrm{Ca}$, доля обменного $\mathrm{Mg}$ также значительна (15-29 \% от суммы) (табл. 3). Показательно, что количество обменного $\mathrm{NH}_{4}^{+}$заметно превышает обменные $\mathrm{Na}$ и $\mathrm{K}$ (иногда на порядок). Техногенные илы отличаются также повышенными (в 2-10 раз) содержаниями $\mathrm{NO}_{3}^{-}$. Наблюдаемые колебания значений емкости поглощения обусловлены пространственными различиями вещественного (особенно гранулометрического и минерального) состава илов. Судя по всему, основными носителями адсорбционных свойств техногенных илов являются аморфное и органическое вещество, гидроксиды железа, карбонатные и (в некоторых случаях) глинистые минералы. Безусловно, обменные реакции играют важную роль в формировании химического состава иловых и придонных вод, способствуя появлению здесь речных вод специфического химического состава.

Таблица 3. Обменные катионы в фоновом аллювии и техногенных речных илах.

Table 3. Exchangeable cations in the background alluvium and technogenic river silts.

\begin{tabular}{|c|c|c|c|c|c|c|}
\hline \multirow{2}{*}{$\begin{array}{c}\text { Место } \\
\text { отбора проб }\end{array}$} & \multirow{2}{*}{$\begin{array}{c}\text { Сумма катионов, } \\
\text { мг-экв/100 г }\end{array}$} & \multicolumn{5}{|c|}{ В \% от суммы катионов: } \\
\hline & & $\mathrm{NH}_{4}^{+}$ & $\mathrm{Na}^{+}$ & $\mathrm{K}^{+}$ & $\mathrm{Ca}^{2+}$ & $\mathrm{Mg}^{2+}$ \\
\hline \multicolumn{7}{|c|}{ Фоновый аллювий } \\
\hline Верховье р. Пахры & 4.84 & 1.03 & 0.21 & 0.62 & 74.79 & 23.35 \\
\hline \multicolumn{7}{|c|}{ Техногенные ильы } \\
\hline Мураниха, аэропорт & 34.72 & 5.39 & 0.20 & 0.26 & 74.02 & 20.13 \\
\hline Петрица, верховье & 38.61 & 3.96 & 0.49 & 1.11 & 71.10 & 23.34 \\
\hline Петрица, верховье & 41.35 & 3.53 & 0.27 & 0.85 & 80.24 & 15.11 \\
\hline Петрица, Климовск & 34.94 & 0.69 & 0.32 & 1.14 & 78.56 & 19.29 \\
\hline Петрица, Климовск & 14.19 & 0.70 & 0.14 & 0.42 & 74.07 & 24.67 \\
\hline Петрица, Климовск & 18.31 & 0.76 & 0.22 & 0.82 & 76.30 & 21.90 \\
\hline Петрица, Климовск & 32.92 & 1.33 & 0.15 & 0.73 & 81.87 & 15.92 \\
\hline Устье Петрицы & 24.25 & 1.49 & 0.16 & 0.58 & 68.95 & 28.82 \\
\hline Среднее & 29.91 & 2.23 & 0.24 & 0.74 & 75.63 & 21.15 \\
\hline
\end{tabular}

В общем случае техногенные илы характеризуются достаточно высокой емкостью поглощения (обмена) катионов, изменяющейся от 14 до 41 мг-экв/100 г (среднее 30). Для сравнения, емкость поглощения катионов илистой фракции (<0.001 мм) дерново-подзолистых почв, широко развитых в бассейне р. Пахры, находится в пределах 36-56 мг-экв/100 г (Горбунов, 1963). Емкость катионного обмена каолинита составляет 3-15 мг-экв/100 г, монтмориллонита - 80-150, иллита - 10-40, вермикулита - 100-150, хлорита - 10-40, органического вещества - 150-500 мг-экв/100 г (Грим, 1967), донных отложений р. Дамодар (Индия) - 12.5 мг-экв/100 г (Бабенков, 1977). Изучение обменного комплекса отложений Иваньковского водохранилища (Московская область) показало, что среднее значение суммы обменных катионов для песков составляет 3.8, для серых илов - 48 мг-экв/100 г (Бреховских и др., 200). Близкие значения установлены для донных отложений днепровских водохранилищ (Паламарчук, 1972).

Таким образом, техногенные речные илы характеризуются (по сравнению с фоновым аллювием) высокими значениями сухого остатка, высокой обменной кислотностью и значительными содержаниями обменных ионов. Наибольшие значения емкости обмена катионов закономерно характерны для отложений с низкими значениями $\mathrm{pH}$. Во всех отложениях в составе обменных катионов доминирует (69-82 \% от суммы) Са, доля обменного $\mathrm{Mg}$ также значительна (15-29 \%). Количество обменного $\mathrm{NH}_{4}^{+}$заметно превышает содержание обменных $\mathrm{Na}$ и $\mathrm{K}$. Техногенные речные илы отличаются существенно повышенными содержаниями $\mathrm{NO}_{3}^{-}$. Наблюдаемые колебания значений ем- 
кости поглощения обусловлены местными пространственными различиями вещественного состава отложений, а также уровнем содержания и особенностями группового состава содержащегося в них органического вещества. Основными носителями адсорбционных свойств техногенных речных илов являются аморфное и органическое вещество, гидроксиды железа, карбонатные и глинистые минералы, тонкодисперсные (илисто-глинистые) минеральные частицы. Повышенная емкость поглощения, свойственная техногенным речным илам (по сравнению с фоновым аллювием), обусловливает их намного более высокую удерживающую способность по отношению к химическим элементам и органическим соединениям, что, с одной стороны, отчасти снижает доступность загрязняющих веществ для гидробиотов, с другой - свидетельствует о значимости техногенных илов как долговременного вторичного источника загрязнения речной системы.

\section{Литература}

1. Алексеева Т.А., Теплицкая Т.А. Спектрофлуориметрические методы анализа ароматических углеводородов в природных и техногенных средах. Л. Изд-во: Гидрометеоиздат. 1981. 216 с.

2. Бабенков Е.Д. Очистка воды коагулянтами. М. Изд-во: Наука. 1977. 356 с.

3. Бреховских В.Ф., Казмирук Т.Н., Казмирук В.Д. Донные отложения Иваньковского водохранилища: состояние, состав, свойства. М. Изд-во: Наука. 2006. 176 с.

4. Гедройц К.К. Избранные сочинения в трех томах. Т. 1. М. Изд-во: Сельхозгиз. 1955. 559 с.

5. Горбунов Н.И. Высокодисперсные минералы и методы их изучения. М. Изд-во: АН СССР. 1963. 302 с.

6. Грим Р. Минералогия и практическое использование глин (пер. с англ). М. Изд-во: Мир. 1967. 511 с.

7. Паламарчук И.К. О составе обменных катионов в грунтах днепровских водохранилищ // Гидробиологический журнал. 1972. № 5. С. 75-79.

8. ПНН Ф 16.1:2.21-98. Количественный химический анализ почв. Методика выполнения измерений массовой доли нефтепродуктов в пробах почв и грунтов флуориметрическим методом с использованием анализатора жидкости «Флюорат-02». М. Изд-во: МПР РФ. 2007. 26 с.

9. $\quad$ Практикум по агрохимии. М. Изд-во: МГУ. 2001. 689 с.

10. Сидоренко О.В., Метлова И.Ф. Рентгенографический фазовый полуколичественный анализ (РФпКА) осадочных пород // Матер. VII конференции «Геология и минеральные ресурсы Западно-Европейской плиты и ее складчатого обрамления». Тюмень. 1989. С. 59.

11. Янин Е.П. Техногенные илы в реках Московской области (геохимические особенности и экологическая оценка). М. Изд-во: ИМГРЭ. 2004. 95 с.

12. Янин Е.П. Особенности минерального состава русловых отложений реки Пахры (Московская область) в зонах техногенного воздействия // Бюлл. МОИП. Отдел Геол. 2007. Вып. 5. С. 48-55.

13. Янин Е.П. Техногенные речные илы (вещественный состав, геохимические особенности, экологическая оценка) // Экологическая экспертиза. 2013. № 1. С. 2-196.

14. Янин Е.П. Техногенные илы как вторичный источник загрязнения речных вод // Проблемы окружающей среды и природных ресурсов. 2015. № 9. С. 17-25.

15. Yanin E.P. Material Composition and Geochemical Characteristics of Technogenic River Silts // Geochemistry International. 2019. V. 57. №. 13. P. 1361-1454. DOI: 10.1134/S0016702919130020. 